\title{
Birthing a New Journal: Why Bother?
}

\author{
Christopher P. Morley, PhD
}

Published: 2/8/2017 | DOI: 10.22454/PRiMER.2017.1.4

\begin{abstract}
Human knowledge is an imprecise thing, subject to the vicissitudes of bias, misunderstanding, disciplinary boundaries, and power imbalances. Of course, "The Enlightenment," and the scientific method that emerged from it, produced an image of the scientist as the discoverer of new knowledge, using processes that were meant to eliminate human bias and subjectivity. Hence the birth of Positivism, and all the assumptions that lie within.
\end{abstract}

Fortunately, the scholarly community, to a greater or lesser extent, generally understands that as long as humans are conducting research, it will be subject to some level of bias, even under the best of circumstances. For example, even physicists and mathematicians may introduce bias into research simply through selecting what models or hypotheses to test. No field is completely immune, certainly not educational research. ${ }^{1}$

This leaves us, as a scholarly community of primary care medical educators, researchers, and evaluators, with a thorny set of problems. What counts as new or useful knowledge? What deserves to be published - and who should decide?

Surely, publishing a manuscript is difficult enough, owing to the combined necessity of methodological rigor, clear writing, justification and question framing via a useful review of the relevant literature, observation of ethical requirements such as human and animal subject protection, data integrity, and so forth. Added atop these "standard" challenges, one must navigate the selection of the "right" journal, and go through the thoroughly subjective processes of peer and editorial review. So, we might divide the difficulties into a "Type 1" (research is difficult under the best circumstances) and a "Type 2" (professional judgements about what deserves to be published, and in what venue, peer and editor subjectivity, journal fit, etc.).

Given both Type 1 and Type 2 challenges, why bother try to publish a manuscript in a peer-reviewed journal in the first place? Well, that may be a fair question, but one which has several answers. First, perhaps the most obvious is that if a group is working on something worthwhile for the education, training, or career development of primary care learners, and have generated evidence that their approach works, this is useful information to share with those engaged in similar pursuits. Additionally, each peer-reviewed manuscript serves as a basis for being able to say, "I have worked in this area." It becomes, in effect, an additional credential, whether for an individual's career and curriculum vita, or to demonstrate to a granting agency that a group has a proven approach. A peer-reviewed, published paper also serves as the gold standard to measure scholarly activity within a medical school department or residency program. Like it or not, within medicine and similar fields, conference posters, abstracts, book chapters, local CME talks-none count like a peer-reviewed journal article. Unfortunately, these difficulties sometimes mean that experienced scholars don't bother publishing small studies, pilot work, or projects that yield negative results, often for reasons owing to Type 2 difficulties. In those cases, the study may be well-conducted and written, but finding a venue may be hard. Additionally, for novice scholars, both Type 1 and Type 2 issues may be at hand, presenting a seemingly insurmountable wall to publication. Neither the experienced nor the novice scholar truly wants to run their manuscript into a hailstorm of criticism and rejection.

There are ways around both Type 1 and Type 2 challenges. Unfortunately, the way around Type 1 challenges (ie, publishing a paper that has severe methodological, ethical, or grammatical problems) is to, basically, push bad scholarship into the public domain. This is often now happening through predatory or vanity-press journals, although just as often, I suspect those who publish in such journals do not even realize they are getting an easy (but costly) ride. ${ }^{2-4}$ 
"Peer-reviewed Reports in Medical Education Research" (PRiMER) was founded" as an extension of the STFM Resource Library $^{6}$, as an effort to address Type 2 difficulties, while holding fast against Type 1 quality issues. We hope to remove questions of suitability by being clear about the scope of what we review-original research, that follows rigorous research standards, ethical protections, and clear professional writing, focusing upon the education, training, and professional development of primary care providers, and the policies that affect the primary care workforce. As long as a paper is within scope, and applies rigorous methods and interpretation, we are not concerned with overall study size, under-recruitment, negative results, confirmatory findings, and so forth. Of perhaps obvious importance is the modesty we see in the interpretation and implications of small studies, as well as very clear and complete description of all study limitations. Additionally, we strive to return comments from reviewers and editors to submitting authors that are clear, and constructive, attempting to describe a path forward toward eventual publication whenever possible. Also importantly, we maintain an open-access model similar to Family Medicine, and we do not charge authors to publish. This means there is no barrier to access either one's own paper, or other examples of previously published work; there is no cost barrier for the author; and there is absolutely no financial bearing on the decision by the editors to publish or not publish a paper.

Along the path of developing the new journal, we have also had the opportunity to incorporate design aspects that should prove to be both state-of-the-art, as well as helpful to newer authors. These include:

- a web platform that incorporates an author-friendly, responsive design philosophy in its construction;

- the inclusion of an Altmetric ${ }^{7}$ badge and analytic function, which allows authors, editors, publishers, and readers to measure the social media impact of an individual article; and

- the inclusion of links to Mendeley ${ }^{8}$ for easy import of bibliographic data (with plans to add links to other bibliographic management systems in the future).

The approach, design, and philosophy that led to the structure and form of PRIMER was a shared effort. I am very proud to include a production manager and several associate editors on the team, including:

- Traci Nolte, CAE, Society of Teachers of Family Medicine,

- Kristen Bene, PhD, Poudre Valley Hospital/Fort Collins Family Medicine

- Amy Lee, MD, Tufts University

- Julie Phillips, MD, MPH, Michigan State University

- Jacob Prunuske, MD, MSPH, Medical College of Wisconsin

- Andrea Wendling, MD, Michigan State University

In addition to these individuals, we received input from Dr Jana Zaudke, the Communications and Research Committees of STFM, and editors and board members from the journal Family Medicine. We also received feedback from open sessions at STFM meetings, and at the AAFP-sponsored Program Directors Workshop in 2016. In short, PRiMER not represent a singular vision, but rather the hard work and input of many individuals from a variety of perspectives across STFM.

By being clear about our scope, and instructive and rigorous on Type 1 issues, we believe we can help both novice and experienced scholars overcome the activation energy necessary to submit a manuscript to PRiMER. We intend to help potential authors overcome Type 2 issues because, as an electronic journal, we do not have to worry about choosing between which paper warrants taking up costly space in a print copy. Because we stress a brief report style, we encourage quick submission, review, and decisions. Because we don't sell subscriptions or calculate an impact factor, we do not have to worry about whether an article will make a "splash." We simply seek good, rigorous research that incrementally adds to the conversation, pulls bits of knowledge out of the dark corners of the "file drawer," 9,10 and presents a lower bar for entry through an instructive experience for newer authors. Aiming for eventual Medline inclusion, we intend to place PRiMER into an open niche for the dissemination of primary care education research, somewhere between "conference presentation" and "submission to traditional print journal." We hope you will join us on this new venture, as reviewers, authors, mentors, and readers.

Corresponding Author

Christopher P. Morley, PhD 
Interim Chair, Department of Public Health \& Preventive Medicine, Vice Chair for Research, Department of Family Medicine Associate Professor of Family Medicine, Public Health \& Psychiatry S.U.N.Y. Upstate Medical University

morleycp@upstate.edu (mailto:morleycp@upstate.edu)

\section{Author Affiliations}

Christopher P. Morley, PhD - S.U.N.Y. Upstate Medical University

\section{References}

1. Hyslop-Margison EJ. Scientific Paradigms and Falsification: Kuhn, Popper, and Problems in Education Research. Educ Policy. 2010;24(5):815-31. doi:10.1177/0895904809339166

2. Beall J. Predatory publishers are corrupting open access. Nature. 2012 Sep 13;489(7415):179. doi:10.1038/489179a

3. Beall J. Best practices for scholarly authors in the age of predatory journals. Ann R Coll Surg Engl. 2016;98(2):77-9. doi:10.1308/rcsann.2016.0056

4. Morley CP. “Dear Esteemed Author:” Spotting a Predatory Publisher in 10 Easy Steps [Internet]. STFM Blog. 2016. Available from: https://blog.stfm.org/2016/05/23/predatory-publisher/

5. Morley CP, Nolte T. STFM Launches a New Journal Focused on Family Medicine Education: Peer-Reviewed Reports in Medical Education Research (PRIMER). Ann Fam Med. 2016 Sep 1;14(5):478-9. doi:10.1370/afm.1987

6. STFM Resource Library [Internet]. [cited 2017 Jan 17]. Available from: http://resourcelibrary.stfm.org/home

7. Discover the attention surrounding your research - Altmetric [Internet]. [cited 2017 Feb 3]. Available from: https://www.altmetric.com/

8. The Mendeley Support Team. Getting Started with Mendeley [Internet]. Mendeley Desktop. London: Mendeley Ltd.; 2011. p. 1-16. Available from: http://www.mendeley.com

9. Franco A, Malhotra N, Simonovits G. Publication bias in the social sciences: Unlocking the file drawer. Science (80- ). 2014 Sep 19;345(6203):1502-5. doi:10.1126/science.1255484

10. Rosenthal R. The file drawer problem and tolerance for null results. Psychol Bull. 1979;86:638-41. doi:10.1037/0033-2909.86.3.638

Copyright $\odot 2017$ by the Society of Teachers of Family Medicine 